\title{
Analisis Sistem Dan Prosedur Akuntansi dalam Pemberian Kredit Produktif pada PT. Bank Pembangunan Daerah Jambi Cabang Muara Bulian
}

\author{
Fauziah $^{1 *}$, Albetris ${ }^{2}$ \\ ${ }^{1}$ STIE Graha Karya Muara Bulian \\ ${ }^{2}$ Universitas Batanghari Jambi \\ *Correspondence email: fauziahh.stiegk@gmail.com, albetris90@gmail.com
}

\begin{abstract}
Abstrak. Mengtahui sistem dan prosedur akuntansi secara jelas dan akurat agar pelaksanaan pemberian kredit secara selektif dan tepat sasaran, terutama kredit produktif terhadap debitur pada PT. Bank Pembangunan Daerah Jambi Cabang Muara Bulian, merupakan tujuan dari penelitian ini. Pelaksanaan pemberian kredit secara efektif dan efisien dapat terlaksana dengan baik sesuai dengan standar dan peraturan yang berlaku secara umum maupun khusus. Membandingkan pendapat para ahli atau referensi yang dijadikan pedoman atau petunjuk teknis dengan pelaksanaan yang ada dalam penelitian ini, dan menguraikan secara rinci kronologis dari hasil penelian ini dengan metode deskriptif kualitatif. Sehingga didapati hasil yang jelas dan terinci dari penelitian ini yang di tunjukkan bahwa sistem dan prosedur yang di jalankan oleh PT. Bank Pembangunan Daerah Jambi Cabang Muara Bulian dalam pelaksanaan pemberian kredit, terutama kredit produktif dapat terlaksana dengan baik sesuai dengan prinsip dan standar yang berlaku. Hingga tujuan untuk memberikan pelayanan yang terbaik dan dapat memilih debitur yang tepat sasaran sehingga pemberian kredit produktif dapat terlaksana secara efektif dan efisien, sesuai dengan yang di harapkan.
\end{abstract}

Kata Kunci: system; prosedur akuntansi; kredit produktif

\begin{abstract}
Know the accounting system and procedures clearly and accurately so that the implementation of credit disbursement is selective and on target, especially productive credit to debtors at PT. Jambi Regional Development Bank Muara Bulian Branch, is the purpose of this research. The implementation of credit disbursement effectively and efficiently can be carried out properly in accordance with the standards and regulations that apply in general and in particular. Comparing the opinions of experts or references that are used as guidelines or technical instructions with the implementation in this research, and describe in detail the chronological details of the results of this research with qualitative descriptive methods. So that clear and detailed results are obtained from this research which shows that the systems and procedures that are run by PT. Jambi Regional Development Bank Muara Bulian Branch in the implementation of lending, especially productive credit, can be carried out properly in accordance with applicable principles and standards. Until the goal is to provide the best service and be able to choose the right debtors so that the provision of productive credit can be carried out effectively and efficiently, as expected.
\end{abstract}

Keywords: system; accounting procedures; productive credit

\section{PENDAHULUAN}

Perbankan di Indonesia dalam peranan pentingnya dapat membantu Negara dalam peningkatan perekonomian, yaitu sebagai lembaga keuangan. Pada hakikatnya, perbankan berdiri untuk tujuan memberi kemudahan bagi nasabah untuk memanfaatkan pelayanan yang diberikan, terutama untuk transaksitransaksi keuangan, dan bantuan perolehan modal usaha atau kredit dalam dunia bisnis. Bukanlah bank, jika keberadaanya tidak disertai dengan kegiatan usaha komersil melalui penggunaan asetnya, sehingga dapat menpai tujuan yang diinginkan secara efektif dan efisien.

Bagaimana disebutkan dalam Undang-Undang No.10 Tahun 1998 (Presiden Republik Indonesia, 1998) dapatlah dipahami bahwa, dalam menjalankan usahanya berusaha menghimpun dana dari masyarakat dan untuk disalurkan kembali kepada masyarakat melalui produk yang dimiliki, dengan cara demikian bank dapat membantu masyarakat dalam peningkatan modal usaha dan dapat menarik keuntungan.
Undang-Undang No.10 tahun 1998 juga memberikan pemahaman bahwa Kredit adalah bank menyediakan produk berentuk pinjaman dan melakukan penagihan, atau dengan kata lain adalah pinjaman yang harus dibayar berdasarkan persetujuan atau kesepakatan dalam kontrak/perjanjian pinjaman antara bank dengan pihak Nasabah/Konsumennya dengan waktu yang telah ditentukan dan disetujui bersama.

\section{Pengertian Sistem}

Sistem bila dilihat dari bahasa Latin (systema) dan bahasa Yunani (sustema); dapat diartikan bahwa sistem merupakan suatu kesatuan yang terdiri dari komponen atau elemen yang dihubungkan bersama untuk memudahkan aliran informasi, materi atau energi untuk mencapai suatu tujuan. Sehingga dapat menggambarkan bahwa sistem merupakan suatu entitas yang berinteraksi.

Pendapat umum para ahli yaitu (Dewi et al., 2021; Fimanto \& Rani, 2021; Firdaus et al., 2021; Prasesti et al., 2021; Sulistiani et al., 2021; Ulyah \& Istikhoroh, 2021) yang di rangkum bersama bahwa sistem dapat 
diartikan sebagai kumpulan dari elemen-elemen yang saling berhubungan antara satu dengan yang lainnya untuk mencapai suatu tujuan tertentu sebagai satu kesatuan yang utuh dalam mencapai tujuan bersama. Tujuan bersama tersebut dapat dilaksanakan dengan melalui cara pengoperasian barang dan data pada saat tertentu, sehungga tujuan bersama dapat terpenuhi dengan mendapatkan data dan informasi yang jelas dan akurat.

\section{Pengertian prosedur}

Prosedur mempunyai penjelasan yang berbeda dengan sistem secara umum, maka kita perlu membedakan antara sistem dan prosedur, dapat kita pahami perbedaan tersebut dari beberapa pendapat para ahli, yaitu (Husna et al., 2021; Prasasti, 2021; Saputri \& Utomo, 2021; Wulandari et al., 2021); memberikan pemahaman dari pendapat para ahli, prosedur merupakan suatu urutan kegiatan atau aktivitas klerikal, yang biasanya dapat melibatkan beberapa orang dalam suatu organisasi atau departemen, dengan upaya agar penanganan transaksi perusahaan yang seragam, dan terjadi berulang-ulang.

Perbedaannya prosedur merupakan bagian dari suatu sistem yang mana prosedur-prosedur tersebut saling keterkaitan dan saling mempengaruhi antara satu dengan yang lainnya.

Berdasarkan pendapat para ahli tersebut dapat di ambil kesimmpulan bahwa prosedur merupakan suatu urutan atau tata cara dalam menyelesaikan suatu pekerjaan terpola dan waktu yang telah di tentukan.

\section{Pengertian Akuntansi}

Penjelasan Kamus Besar Bahasa Indonesia (KBBI) memberikan pemahaman bahwa Akuntansi merupakan perpaduan antara teori dan praktik-praktik perakutansian antara lain; perakunan, termasuk tanggung jawab, prinsip, standar, kelaziman (kebiasaan), dan semua kegiatannya, atau seni pencatatan dan pengikhtisaran transaksi keuangan dan penafsiran akibat suatu transaksi terhadap suatu kesatuan ekonomi. Menurut beberapa para ahli pengertian akuntansi diantaranya adalah :

(Alviolita \& Yunus, 2021; Yusnaldi, 2021; Yussianawati et al., 2021); memberi pemahaman bahwa akuntansi adalah suatu proses mencatat, mengidentifikasi dan mengkomunikasi semua transaksi ekonomi perusahaan. Pendapat (Karenina \& Surya, 2021; Setyorini et al., 2021; Yussianawati et al., 2021); punya pemahaman yang lain tentang akuntansi adalah sebuah body of knowledge serta mempunyai fungsi organisasi secara tersusun, orsinil, otentik, menganalisa dan mentafsirkan seluruh kejadian dan transaksi serta analisa keuangan yang akan terjadi dalam kegiatan akuntansi untuk menyediakan informasi yang dibutuhkan manajemen tentang semua laporan dan pertanggung jawaban atas kepercayaan yang diterimanya. Sedangkan menurut keputusan menteri keuangan akuntansi adalah sebuah proses pengumpulan, penganalisaan, pengklarifikasi, pencatatan, pelaporan, dan peringkasan terhadap transaksi keuangan dari kesatuan ekonomi untuk menyediakan informasi keuangan bagi yang membutuhkan informasi tersebut dan digunakan untuk pengambilan suatu keputusan.

\section{Akuntansi perbankan}

Akuntansi perbankan yaitu merupakan proses pencatatan yang dilakukan di ruang lingkup perbankan itu sendiri, dengan menggunakan akun-akun, melakukan pengklasifikasian dari hasil pencatatan yang dilakukan dari akun yang berbeda-beda, dan dilanjutkan dengan penganalisaan terhadap data dan laporan keuangan serta melakukan penafsiran data dan laporan keuangan perbankan tersebut, yang mana akuntansi keuangan dan akuntansi perbankan saling keterkaitan sesuai dengan Pernyataan Standard Akuntansi Keuangan (PSAK No. 31) (Beribe \& Sondakh, 2020; Chandra, 2012) tentang Akuntansi Perbankan, dengan tetap mengacu pada prinsip dan standar yang berlaku dan di terima secara umum pada bisnis perbankan dan dapat dijadikan acuan sebagai petunjuk dan teknis pelaksanaan.

\section{Perkreditan}

Di Indonesia, perbankan pada umumnya mempunyai produk jasa perkreditan untuk memberikan pelayanan terbaiknya terhadap nasabah. Kredit produktif merupakan salah satu produk bank untuk meningkatkan produksinya dan menambah aset melalui pendapatan laba dari kredit produktif. Pemberian jasa kredit harus dilaksanakan dengan selektif dan disertai rasa penuh keyakinan. Sesuai dengan istilah kredit itu sendiri mempunyai arti percaya atau kepercayaan, sesuai dengan penjelasan diatas disebutkan bahwa dalam pemberian kredit pihak bank harus mempunyai keyakinan, sehingga dapat dipahami keyakinan timbul karna ada rasa percaya terhadap nasabah melalui hasil analisa.

\section{Fungsi Kredit}

Kredit mempunyai fungsi dan peranan yang sangat penting dalam perekonomian, fungsi dan peranan kredit dalam perekonomian, keuangan, dan perdagangan, antara lain; dapat meningkatkan utility dari modal dan barang, meningkatkan peredaran dan lalu lintas uang, alat stabilitas dan hubungan ekonomi, dan memberikan kegairahanberusaha bagi masyarakat.

\section{Jenis-jenis kredit}

Kredit juga mempunyai bermacam-macam jenis yang dibedakan berdasarkan sudut pandang dan cara pendekatannya yang berbeda-beda, dari beberapa pendekatan (Nurjanah \& Supriatna, 2021; Yulientinah \& Siregar, 2021) dapat diuraikan jenis kredit sesuai menurut pendekatannya masing-masing yaitu ; 
1. Jenis kredit berdasarkan tujuan kegunaannya, yaitu kredit; Investasi, modal kerja, konsumsi, dan serba guna.

2. Jenis kredit berdasarkan jangka waktu, yaitu; jangka pendek, menengah, dan jangka panjang.

3. Jenis kredit berdasarkan tujuan kredit, yaitu; konsumtif, produktif, modal kerja/perdagangan, dan investasi berdasarkan tujuan kredit.

4. Jenis kredit berdasarkan, jaminan, mempunyai beberapa bentuk, yaitu: orang, efek, barang, dan dokumen.

5. Jenis kredit berdasarkan bentuk; yaitu; rekening koran bebas, rekening koran terbatas, rekening koran aflopend, revolving kredit, dan term loans.

6. Berdasarkan jenis sektor usaha, yaitu ; pertanian, perindustrian, pertambangan, ekspor impor, koperasi, profesi, dan perumahan.

\section{Prinsip-Pinsip Kredit}

Bank pada umumnya dalam pelaksanaan pemberian kredit harus selektif, sebelum pelaks dinaan penyaluran kredit hendaklah pihak bank harus yakin terlebih dahulu bahwa kredit yang diberikan harus kembali sesuai dengan yang diharapkan. Untuk mendapatkan keyakinan pihak bank harus melakukan penelitian dan penganalisaan calon nasabah/debitur danl prosedur penilaian yang telah di laksanakan. Prosedur penilaian harus mempunyai standar dan kriteria-kriteria penilaian, agar dapat tercapai hasil yang diinginkan dapat tercapai dengan baik (Farihah et al., 2021; Iqbal, 2021).

Pelaksanaan penilaian pada umumnya yang dilakukan oleh bank mengacu pada kriteria penilaian agar benar-benar dapat menentukan nasabah yang layak dan pantas untuk diberi kredit, kriteria pelaksanaan penilaian tersebut dengan mengacu pada analisis $5 \mathrm{C}$ dan $7 \mathrm{P}$.

Analisis 5C tersebut diantaranya dapat di jelaskan sebagai berikut:

Character, merupakan analisa yang sangat penting bagi calon debitur karna berkaitan dengan watak dan sifat seseorang. Watak atau sifat dari seseorang yang akan diberikan kredit harusbenar-benar yang dapat dipercaya. Dalam menganalisis bank meyakini benar bahwa calon debiturnya memiliki reputasi baik, bahwa nasabah selalu menepati janji dan tidak terlibat hal-hal yang berkaitan dengan kriminalitas, antara lain penjudi, pemabuk, atau penipu. Watak atau sifat dari calon debitur dapat diketahui dari latar belakang nasabah, baik latar belakang pekerjaan maupun pribadi misalkan; dari gaya hidupnya, keadaan keluarga, dan hoby.

Capacity (Capability), analisis yang berkaitan dengan kemampuan nasabah dalam membayar kredit, bank harus mengetahui secara jelas kemampuan calon debitur dengan melakukan penilaian dari nperkembangan usahanya dari waktu ke waktu, apakah mengalami perkembangan atau mengalami penurunan dari waktu kewaktu.

Capital, suatu kondisi kekayaan / harta yang dimiliki oleh calon debitur, bank harus menganalisa modal calon debitur bsik besarnya/kemampuannya maupun strukturnya. Melihat penggunaan modal apakah efektif, pihak bank dapat melihat dari laporan keuangan yang disajikan dengan melakukan pengukuran dari segi likuiditas, solvabilitas, dan rentabilitas serta pengukuran lainnya.

Condition, kondisi ekonomi harus di analisa dengan prospek usaha calon debitur, upaya tersebut agar dapat mengindari terjadinya kredit yang bermasalah atau kredit macet, dengan analisa kondisi tersebut kredit bermasalah relatif kecil.

Collateral, analisis kolateral merupakan jaminan yang diberikan oleh calon nasabah dalam pengajuan kreditnya baik yang bersifat fisik maupun yang nonfisik. Nilai jaminan haruslah melebihi jumlah kredit yang diajukan. Jaminan harus diteliti kebenaran dan keabsahannya, sehingga kemungkinan terjadi sesuatu yang tidak diinginkan dapat dihindari.

Selanjutnya penilaian suatu kredit dapat pula dilakukan dengan analisis $7 \mathrm{P}$ kredit dengan unsur penilaian sebagai berikut:

Personality, penilaian terhadap kepribadian atau tingkah laku nasabah dari kesehariannya, kehidupan pribadiaannya di masa lalu, analisis personality mencakup sikap, emosi, dan tingkah laku serta tindakan nasabah dalam menghadapi dan menyelesaikan masalah kehidupannya.

Party, penilaian klasifikasi nasabah ke dalam atau golongan tertentu berdasarkan kemampuan, loyalitas, serta kebiasaan nasabah dapat digolongkan dan diberikan fasilitas kredit yang berbeda oleh bank.

Perpose, penilaian bertujuan untuk mengetahui apakah nasabah mengajukan kredit sesuai dengan jenis kredit yang diinginkannya. Pengambilan kredit mempunyai tujuan yang bermacam-macam sesuai dengan kebutuhan. Misalnya untuk modal kerja, investasi, konsumtif, dan produktif.

Prospect, untuk menilai apakah prospek usaha nasabah di masa yang akan datang akan menguntungkan atau tidak, hal ini penting agar fasilitas kredit yang dibiayai tidak mempunyai prospek, sehingga dapat berakibat kerugian pada kedua belah pihak.

Payment, mengamati dan mengukur kemampuan nasabah dalam mengembalikan kredit, hal ini dapat diukur dari usaha yang dimiliki oleh calon debitur. Banyaknya sumber usaha atau penghasilan debitur maka kemampuan pengembalian atau pembayaran kreditnya lebih besar..

Profitabillity, menganalisis sampai dimana kemampuan nasabah dalam memperoleh laba atau keuntungan. Profitability diukur dari pendapatan periode ke periode berikutnya, apakah mengalami peningkatan, 
diam ditempat, mengalami penurunan, jika ditambah dengan kredit yang akan diperolehnya.

Protection, bertujuan agar dapat menjaga kredit yang diberikan mempunyai jaminan perlindungan, sehingga kreditur dan debitur terlindungi dari resiko yang tidak diinginkan, ontohnya perlindungan asuransi.

\section{Pengertian produktif}

Produktif meurut Kamus Besar Bahasa Indonesia (KBBI) dapat kita pahami adalah sesuatu yang bersifat atau mampu menghasilkan (dalam jumlah besar), yang mendatangkan (memberikan hasil, manfaat dan sebagainya) atau juga disebut dapat menguntungkan.

Produktif juga mempunyai definisi yang berbeda namun mempunyai kesamaan oleh beberapa para ahli, diantaranya yaitu:

(Nazar \& Surya, 2021) berpendapat bahwa produktif adalah merupakan nisbah atau rasio antara hasil kegiatan (output) dan segala pengorbanan (biaya) untuk mewujudkan hasil tersebut (input).

Menurut (Iskandar et al., 2021) produktif adalah merupakan suatu konsep yang menujukkan adanya kaitan antara hasil kerja dengan satuan waktu yang dibutuhkan untuk menghasilkan produk seorang tenaga kerja.

(Aliyah, 2021) berpendapat bahwa produktif merupakan suatu ukuran yang menyatakan bagaimana baiknya sumber daya diatur dan dimanfaatkan untuk mencpai hasil yang optimal.

Dapat diambil kesimpulan dari beberapa pendapat diatas bahwa kredit produktif adalah suatu kredit yang mempunyai tujuan untuk membantu debitur dalam mencapai tujuannya, apabila tanpa kredit tersebut tidak dapat terwujud. Kredit produktif merupakan salah satu bentuk kredit yang mempunyai tujuan memperlancar proses produksi, mulai dari saat pengumpulan bahan mentah, pengolahan, hingga sampai kepada proses penjualan hasil produksi.

\section{METODE}

Dalam penelitian ini penulis menggunakan metode analisis yang disesuaikan dengan tujuan penulisan dan menggambarkan/mendeskripsikan serta menganalisis suatu kejadian dengan cara menguraikan dan menjelaskan pada pokok masalah yang berkaitan dengan masalah penelitian ini.

\section{Objek Penelitian}

Penelitian tentang analisis system dan prosedur akuntansi dalam pemberian kredit produkstif terhadap nasabah/debitur. Peneliti melakukan analisis pelaksanaan perkreditan pada PT. Bank Pembangunan Daerah Jambi Cabang Muara Bulian.

Dengan mengacu pada variable yang di teliti yaitu sistem dan prosedur pemberian kredit, pada pelaksanaan pemberian kredit tersebut juga dilakukan perhitugan nilai jaminannya dan besarnya angsuran pengembalian hutang.

\section{Jenis Dan Sumber Data Jenis Data}

Dalam penelitian ini untuk menghimpun data yang dibutuhkan, maka penulis menggunakan beberapa teknik pengumpulan data yaitu sebagai berikut:

Data Primer; menurut pendapat (Neuman, n.d.); data primer merupakan data yang berasal dari sumber aslinya yang didapat dari sumber aslinya atau pertama, data primer tidak tersedia dalam bentuk file atau terkompilasi, harus dicari dengan terjun langsung ke objek dan mendapat informasi melalui narasumber atau dalam istilah teknisnya responden.

Data Sekunder; menurut pendapat (Neuman, n.d.); data sekunder ialah data yang didapat dari informasi yang telah dikumpulkan dari sumbernya, data tersebut sudah siap di pakai dan diperoleh dalam bentuk sudah tercatat dan sudah jadi dokumen yang siap di pergunakan (siap pakai).

\section{Sumber Data}

Perolehan data yang dikumpulkan didapat dari objek penelitian yaitu PT. Bank Pembangunan Daerah Jambi Cabang Muara Bulian.

\section{Metode Pengumpulan Data}

Dalam penelitian ini untuk memaksimalkan analisa maka penghimpunan data yang dibutuhkan dilakukann dengan menggunakan teknik pengumpulan data sebagai berikut:

Metode Observasi; merupakan metode pengamatan secara langsung pada objek yang diteliti, di sini penulis mengamati langsung aktivitas yang dilakukan pada Bank Pembangunan Daerah Jambi Cabang Muara Bulian melalui kegiatan magang.

Metode interview (Wawancara); merupakan metode untuk pengumpulan data dengan cara pertanyaan dan langsung dimintakan jawabann dengan pihak-pihak terkait yaitu bagian keuangan pada PT. Bank Pembangunan Daerah Jambi Cabang Muara Bulian.

Studi Pustaka; kegiatan mengumpulkan dan mempelajari buku-buku atau karya tulis, dan tulisan atau sumber lain yang berhubungan dengan masalah yang dibahas, juga mencari referensi-referensi dari situs yang ada di interenet.

\section{Alat Analisis Data}

Penelitian ini menggunakan metode analisis deskriptif kualitatif, yaitu penelitian dengan menguraikan dan mendiskripsikan dari hasil penelitian dalam bentuk analisis. Teknik analisis data yang digunakan yaitu dengan cara membandingkan antara hasil dokumentasi yang diperoleh yang berkaitan dengan pemberian kredit pada Bank yang diteliti dan teori mengenai pemberian kredit dengan fakta yang 
sesungguhnya yang terjadi di lapangan, hasil analisis yang di dapat tersebut ditarik suatu kesimpulan yang berkaitan dengan masalah yang diteliti.

\section{HASIL DAN PEMBAHASAN}

Sistim Dan Prosedur Akuntansi dalam Pemberian Kredit Produktif PT. Bank Pembangunan Daerah Jambi Cabang Muara Bulian

Aktivitas penghimpunan dana adalah sarana bank agar dapat memberikan kemudahan dan keamanan bagi masyarakat, begitu juga dengan kegiatan penyaluran dana kepada masyarakat/nasabah yang membutuhkan. Kredit suatu produk yang banyak memberikan andil bagi perkembang perekonomian masyarakat dengan memberikan pelayanan berupa kredit kepada masyarakat umum, aktivitas perkreditan ini tidak akan terlaksana jika tidak ada suatu kepercayaan diantara pihak yang saling berhubungan, untuk menghindari terjadinya penyelewengan yang tidak sesuai dengan kode etik dan melanggar peraturan perkreditan yang berlaku.

Dalam kegiatan perkreditan ini sistem dan proses dilakukan secara terpola mengacu pada standar dan prinsip pelaksanaannya. Dengan melalui beberapa tahapan yang dilakukan pihak bank untuk meningkatkan pelayanan agar target yang ingin dicapai dalam memberikan kredit terlaksana dengan baik dan tepat, seperti:

1. Pelaksanaan promosi produk bank, pada bagian pemasaran memberikan informasi kepada calon nasabah, tentang syarat-syarat permohonan pinjaman,

2. Selanjutnya calon nasabah menyerahkan surat permohonan.

3. Yang mana surat permohonan dilanjutkan kepada pimpinan cabang unutk mendapatkan persetujuan.

4. Berkas permohonan diteliti oleh Account officer, lalu di etimasi bisa berlanjut atau terjadi penolakan.

5. Setelah berkas permohonan selesai diteliti dan hasilnya dipertimbangkan maka nasabah akan dipanggil untuk proses selanjutnya dan penyerahan persyaratan yang dibutuhkan.

6. Selanjutnya taksasi yaitu; melakukan perhitungan terhadap nilai jaminan dan di serahkan pada notaris.

7. Apabila semua prosedur diatas berjalan dengan lancer, pihak marketing akan berkunjung ketempat sesuai alamat jaminan untuk melakukan survey.

8. Apabila survey berhasil dilakukan, account ofiicer melaksanakan, proses pembuatan surat perjanjian kredit dan analisis kredit.

9. Selanjutnya nasabah dipanggil kembali oleh pelaksana admin kredit untuk melakukan posesi perjanjian antara kedua belah pihak dan penanda tanganan akad kredit bermaterai.

10. Selanjutnya pelaksana pencairan dan pelaksanaan pelaporan oleh bagian akuntansi pelaporan.

11.Penanda tanganan perjanjian antar bank dan nasabah disetujui oleh Kepala yang berwenang yaitu bagian operasional dan kepala pemimpin cabang.
Setelah proses selesai, pada hari atau waktu berikutnya, nasabah dipersilahkan datang untuk pengambilan tabungan, agar nasabah dapat melakukan pengambilan uang miliknya pada saat-saat yang diinginkan.

Bagian petugas akun (account officer) melakukan interview terhadap calon debitur guna mendapatkan informasi yang berkaitan dengan jaminan yang akan diberikan pada bank sebagai agunan pada permintaan kredit tersebut yang disepakati dalam perjanjian kredit secara tertulis. Apabila informasi yang di dapat dari debitur dan telah dirasa cukup oleh petugas akun (account officer) maka bagian penaksiran akan melakukan perhitungan terhadap nilai dari agunan akan akan di jaminkan ke bank, apakah layak atau tidak. Tim appraisal ini dalam melakukan proses penilaian dengan melalui analisa oleh Tim yang profesional dengan tetap berpedoman pada dua unsur sebagai berikut:

Pertama; berpedoman pada nilai taksiran, yaitu dengan memperkirakan nilai jual dari aset atau jaminan berdasarkan harga pasar apabila suatu waktu akan di lepas atau dijual ke pasar tidak akan mengalami kerugian.

Kedua; berpedoman pada nilai pasar atau harga jual suatu barang berharga berdasarkan nilai atau harga penawaran pasar, harga sauatu barang atau surat berharga dapat dijual ataupun dibeli sesuai dengan harga pasar, pedoman nilai pasar suatu surat berharga ditentukan oleh nilai penjualan terakhir

Penilaian atau penaksiran jaminan mempunyai aturan yang harus dipedomani, karena jaminan berkaitan dengan status kepemilikannya, misalkan tanah; status kepemilikannnya mempunyai hak hak bagi pemiliknya, antara lain; tanah hak milik, tanah hak guna bangunan dan tanah hak sewa, dengan rincian prosentase penilan yang bherbeda- beda misalnya sebagai berikut:

Bank memberikan nilai sebesar $80 \%$ untuk tanah hak milik, dan tanah hak guna bangunan, sedangkan jaminan tanah hak sewa itu sebesar 50\%. Ketentuan perhitungan penilaian persentanse tersebut, telah di sesuaikan mengacu pada nilai PBB. Penetapan nilai persentase setengah dari harga pasar dan likuidasinya.

\section{Kesesuaian Sistim Dan Prosedur Akuntansi dalam Pemberian Kredit Produktif Pada PT. Bank Pembangunan Daerah Jambi Cabang Muara Bulian.}

Berdasarkan pengamatan terhadap pelaksanaan sistim dan prosedur akuntansi dalam pemberian kredit produktif di atas, secara rinci di analisa mengenai sistem dan prosedur akuntansinya telah sesuai dengan Pernyataan Standar Akuntansi Keuangan No. 31, dan Surat Edaran Bank Indonesia No. 14/26/BKDU tanggal 19 September 2012, serta prinsip dan pedoman yang berlaku secara umum. Dalam penganalisaan yang lebih rinci dan selektif mengacu kepada pada standar analisa yaiyu $5 \mathrm{C}$ dan $7 \mathrm{P}$. Kredit produktip yang diberikan merupakan bantuan pembiayaan dalam menjalankan 
usaha untuk mencapai kemajuan perekonomian dalam proses penyelamatan bisnis. Setelah di telaah dan dianalisa lebih dalam pemberian kredit produktif ini juga telah sesuai dengan peraturan dan ketentuan yang berlaku yang di tetapkan oleh Bank Sentral.

\section{SIMPULAN}

Dari hasil analisa pada pembahasan yang diuraikan diatas, peneliti dapat menyimpulkan sebagai berikut:

1. Dalam pelaksanaan pemberian kredit yang melewati beberapa tahapan-tahapan, dan selanjutnya pengajuan kredit. Pemberian kredit oleh bank berpegang pada pedoman dan aturan pelaksanaan sebagaimana termuat dalam peraturan dan perundang-undangan yang berlaku.

2. Pelaksanaan pemberian kredit sesuai denagn ketetapan dan peraturan yang berlaku baik secara umum maupun secara khusus. Secara umum dalam pelayanan nasabah debitur dan khususnya dalam pemberian kredit dan mengolah agunan/jaminan yang diserahkan oleh debitur sebagai salah satu syarat dalam perjanjian kredit secara efektif dan efesien sesuai dengan prinsip dan peraturan yang berlaku.

\section{DAFTAR PUSTAKA}

Aliyah, M. (2021). PENERAPAN AKUNTANSI PERSEDIAAN OBAT-OBATAN BERDASARKAN PSAP NO. 05 PADA RUMAH SAKIT UMUM DAERAH MAJENE. Journal of Economic, Public, and Accounting (JEPA). https://ojs.unsulbar.ac.id/index.php/jepa/article/vie w/1039

Alviolita, F., \& Yunus, M. (2021). Analisis atas Efisiensi dan Efektivitas Penerapan Sistem Informasi Akuntansi Penjualan Kredit dalam Pengendalian Intern (Surabaya Suites Hotel di Plaza Boulevard ... UBHARA Accounting Journal. http://journal.febubharasby.org/uaj/article/view/40

Beribe, A. I. W., \& Sondakh, J. J. (2020). Analisis penerapan PSAK 23 tentang pendapatan jasa pasien Jaminan Kesehatan (JKN) menurut Standar Akuntansi Keuangan terhadap tarif Rumah Sakit Gunung .... Indonesia Accounting Journal. https://ejournal.unsrat.ac.id/index.php/iaj/article/vi ew/27077

Chandra, B. (2012). Analisis Kebijakan Akuntansi Persediaan terhadap PSAK No. 14 dan IAS 21 tentang Persediaan pada PT. Hantong Precision Manufacturing Batam. Journal of Accounting \& Management Research. http://repository.uib.ac.id/862/

Dewi, A. A., Hidayati, K., \& Rahman, A. (2021). Analisis Sistem Informasi Akuntansi Penerimaan Kas dalam Meningkatkan Sistem Pengendalian Internal (Studi Kasus PT. Nirta Majapahit di
Surabaya). Accounting

Journal.

http://journal.febubhara-

sby.org/uaj/article/view/103

Farihah, R., Halim, M., \& Nastiti, A. S. (2021). Evaluasi Sistem Informasi Akuntansi Pemberian Kredit. BUDGETING: Journal of .... https://journal.ipm2kpe.or.id/index.php/BUDGET ING/article/view/1746

Fimanto, F., \& Rani, U. (2021). Analisis Penerapan Sistem dan Prosedur Akuntansi Aset di Dinas Penanaman Modal dan Pelayanan Terpadu Satu Pintu Kota Magelang. Journal of Economic, Management, Accounting

https://ojs.unsiq.ac.id/index.php/jematech/article/v iew/1343

Firdaus, E., Inayah, N. L., \& ... (2021). Analisis Penerapan Sistem Informasi Akuntansi Penjualan Kredit dalam Rangka Meningkatkan Pengendalian Intern pada Dealer CV. Fortuna Motorindo Sidoarjo. $\quad$... Accounting Journal. http://journal.febubharasby.org/uaj/article/view/59

Husna, G. A., Hidayati, K., \& ... (2021). Analisis Sistem Pengendalian Intern Penerimaan dan Pengeluaran Kas pada PR. Sumber Barokah Sidoarjo. ... Accounting Journal. http://journal.febubharasby.org/uaj/article/view/61

Iqbal, J. (2021). PERANCANGAN SISTEM INFORMASI AKUNTANSI PENJUALAN BERBASIS WEB PADA SAIIOPROJECT JAMBI. Journal of Applied Accounting and Business.

http://ojs.politeknikjambi.ac.id/jaab/article/view/1 62

Iskandar, S., Saman, S., \& Miten, P. K. (2021). A, Analisis ANALISIS SISTEM PENGENDALIAN INTERN ATAS PEMBERIAN KREDIT PADA KSP KOPDIT GURU KELUBAGOLI KECAMATAN KELUBAGOLIT $\ldots . . \quad J E M A$ ADPERTISI JOURNAL. http://jurnal.adpertisi.or.id/index.php/JEMA/articl e/view/109

Karenina, E., \& Surya, R. T. (2021). Analisis Dan Perancangan Sistem Informasi Akuntansi Kas Rumah Sakit Menggunakan Metode SDLC Dan Framework BABOK Versi 3.0. Indonesian Accounting Literacy Journal. https://jurnal.polban.ac.id/ojs3.1.2/ialj/article/view/2554

Nazar, Y. M., \& Surya, R. T. (2021). Perancangan Aplikasi Sistem Informasi Akuntansi Penjualan Menggunakan Software Microsoft Access 2016 (Studi Kasus Toko Diecolz85). Indonesian Accounting Literacy Journal. https://jurnal.polban.ac.id/ojs-

3.1.2/ialj/article/view/2524

Neuman, w. lawrence. (n.d.). basics of social research : 
Fauziah dan Albetris, Analisis Sistem Dan Prosedur Akuntansi dalam Pemberian Kredit Produktif pada PT. Bank Pembangunan Daerah Jambi Cabang Muara Bulian

qualitative \& Quantitative approaches.

Nurjanah, N. Y. S., \& Supriatna, I. (2021). Perancangan Sistem Informasi Akuntansi Simpan Dan Pinjam Pada Koperasi Simpan Pinjam Jaya Kencana (KSPJK). ... Accounting Literacy Journal. https://jurnal.polban.ac.id/ojs-

3.1.2/ialj/article/view/2523

Prasasti, L. (2021). ANALISIS SISTEM INFORMASI AKUNTANSI PENERIMAAN DAN PENGELUARAN KAS PADA PT. ANJUNGAN BUANA WISATA. Journal of Applied Accounting and Business. http://ojs.politeknikjambi.ac.id/jaab/article/view/1 68

Prasesti, G. D., Mahsina, M., \& ... (2021). Analisis Sistem Informasi Akuntansi Penerimaan dan Pengeluaran Kas untuk Meningkatkan Pengendalian Intern "Penjualan Tunai" pada PT. Surya Sejahtera .... ... Accounting Journal. http://journal.febubhara-

sby.org/uaj/article/view/41

Presiden Republik Indonesia. (1998). Undang-Undang Republik Indonesia No. 10 Tahun 1998 Tentang Perbankan. In Lembaran Negara Republik Indonesia.

http://www.bphn.go.id/data/documents/98uu010.p df

Saputri, A. E., \& Utomo, S. P. (2021). ANALISIS SISTEM INFORMASI AKUNTANSI PENGGAJIAN KARYAWAN PADA COOLIO BARBERSHOP CABANG SIDOARJO. Journal of Sustainability Bussiness .... http://jurnal.unipasby.ac.id/index.php/jsbr/article/v iew/3431

Setyorini, R., Rosyafah, S., \& ... (2021). Analisis Penerapan Pengendalian Internal Pemakaian Bahan Baku Guna Meningkatkan Kelancaran Proses Produksi (Studi Kasus pada PT. Cahaya Indah Madya .... ... Accounting Journal. http://journal.febubhara-

sby.org/uaj/article/view/44

Sulistiani, H., Yuliani, A., \& Hamidy, F. (2021). Perancangan Sistem Informasi Akuntansi Upah Lembur Karyawan Menggunakan Extreme Programming. Technomedia Journal. http://ijc.ilearning.co/index.php/TMJ/article/view/ 1421

Ulyah, H., \& Istikhoroh, S. (2021). ANALISIS SISTEM AKUNTANSI PENDAPATAN DALAM PENETAPAN JUMLAH GAJI PEGAWAI (PADA RS SURYA MEDIKA GRESIK). Journal of Sustainability Bussiness

http://jurnal.unipasby.ac.id/index.php/jsbr/article/v iew/3418

Wulandari, A. E., Purwanto, T., \& ... (2021). ANALISIS PENERAPAN SISTEM INFORMASI AKUNTANSI
PENGIRIMAN

UNIT UNTUK MENINGKATKAN EFEKTIVITAS DAN EFISIENSI PADA .... Journal of Sustainability .... http://jurnal.unipasby.ac.id/index.php/jsbr/article/v iew/3436

Yulientinah, D. S., \& Siregar, S. A. (2021). PENGARUH SISTEM INFORMASI AKUNTANSI PERSEDIAAN TERHADAP PENGENDALIAN INTERNAL PERSEDIAAN PADA PT TRIJATI PRIMULA. LAND JOURNAL.

https://ejurnal.poltekpos.ac.id/index.php/jurnallan $\mathrm{d} /$ article/view/1054

Yusnaldi, Y. (2021). PENGARUH ANALISIS SISTEM INFORMASI AKUNTANSI PENJUALAN, PENERIMAAN KAS, DAN PENGELUARAN KAS TERHADAP PENGENDALIAN INTERNAL. Journal of Industrial Engineering \& Management https://jiemar.org/index.php/jiemar/article/view/15 9

Yussianawati, M., Rosyafah, S., \& ... (2021). Analisis Penerapan Sistem Informasi Akuntansi Persediaan Barang Dagang (pada CV. Ambassador Surabaya). $\quad$... Accounting Journal. http://journal.febubharasby.org/uaj/article/view/74 